\title{
Strategi dan Kebijakan dalam Pengelolaan Wisata Konservasi Orangutan Sumatera (Pongo abelii) di Bukit Lawang Kabupaten Langkat Sumatera Utara
}

\section{Strategy and policy in the management of Sumatran Orangutan (Pongo abelii) conservation tourism on the Lawang Hill in the Langkat district of North Sumatera}

Susilawati ${ }^{\mathrm{a}}$, Akhmad Fauzi ${ }^{\mathrm{b}}$, Cecep Kusmana ${ }^{\mathrm{c}}$, Nyoto Santoso ${ }^{\mathrm{d}}$

a Program Studi Ilmu Pengelolaan Sumberdaya Alam dan Lingkungan Institut Pertanian Bogor, Indonesia

b Guru Besar Institut Pertanian Bogor, Departemen Ekonomi Sumberdaya dan Lingkungan, Fakultas Ekonomi dan Manajemen, Indonesia

c Guru Besar Institut Pertanian Bogor, Departemen Sivikultur, Fakultas Kehutanan IPB, Indonesia

d Staf Pengajar Departemen Konservasi Sumberdaya Hutan dan Ekowisata, Fakultas Kehutanan; Program Studi Ilmu Pengelolaan Sumber Daya Alam dan Lingkungan Institut Pertanian Bogor, Indonesia

\section{Article Info:}

Received: 18 - 05 - 2019

Accepted: 26 - 02 - 2020

Keywords:

AHP, Bukit Lawang, ISM, WKOB.

Corresponding Author: Susilawati:

LEMHANNAS RI, J1. Medan Merdeka Selatan No. 10. Jakarta 10110

Email: sisiwitt@yahoo.com

How to cite (CSE Style $8^{\text {th }}$ Edition):

Susilawati, Fauzi A, Kusmana C, Santoso N. 2020. Strategi dan kebijakan dalam pengelolaan wisata konservasi Orangutan Sumatera (Pongo abelii) di Bukit Lawang Kabupaten Langkat Sumatera Utara. JPSL 10(1): 1-11. http://dx.doi.org/10.29244/jpsl.10.1.111.

\section{PENDAHULUAN}

Pariwisata merupakan kegiatan fenomena ritual inversi. Ritual inversi adalah kecenderungan seseorang untuk mengunjungi tempat baru yang berbeda dari lingkungan atau tempat biasa mereka tinggal dalam waktu sementara, bertujuan untuk memperoleh pengalaman dan pengetahuan baru, atau sekedar melepaskan kepenatan. Oleh karena itu, wisatawan akan cenderung mencari tempat-tempat yang indah, unik, serta berbeda dari tempat biasanya mereka hidup untuk sementara (Hermawan, 2017). World Tourism Organization (WTO) mendefenisikan wisata adalah orang yang melakukan perjalanan untuk kesenangan dalam periode waktu tertentu. Ekowisata adalah kegiatan wisata yang berbasis ekologi. Perkembangan ekowisata disebabkan oleh semakin langkanya tatanan alam yang memiliki keaslian dan kekhasan, semakin meningkatnya isu lingkungan hidup, semakin meningkatnya kebijakan negara-negara untuk melindungi potensi alam dan budayanya,

\begin{abstract}
This study aims to analyze the constraints and opportunities of the Bukit Lawang Orangutan Conservation Tourism (WKOB) management and also to formulate an alternative policy strategy in overcoming the obstacles of managing the WKOB. Method used in this research is involving several experts related to this research. The results showed the main constraints in the management of WKOB are the lack of integration of costs and entry fees, poor infrastructure to $W K O B$, lack of facilities, and too many entrances. Other constraints are the lack of stakeholder roles, particularly the local government of Langkat Regency, the lack of strict enforcement of regulations on environment and cleanliness, the lack of information and promotion of tourism, and the low mindset and public awareness of the importance of ecotourism and conservation. The threat of environmental damage to Gunung Leuser National Park, especially river rock mining (the existence of
excavation () in Bahorok river. An alternative strategy to overcome obstacles in managing $W K O B$ is the need for integrated and professional sustainable tourism management.
\end{abstract}


semakin meningkatnya sarana dan prasarana perhubungan baik antar kota, wilayah ataupun antar negara dan semakin meningkatnya kesadaran masyarakat terhadap perlindungan dan pelestarian alam (Alikodra dan Hadi, 2002).

Orangutan telah menjadi salah satu obyek wisata yang menarik. Hal ini karena orangutan (Pongo spp) merupakan salah satu kera besar yang masih bertahan di wilayah Asia Tenggara. Kera besar lainnya hidup di Afrika yaitu gorilla (Gorilla gorrila), simpanse (Pan Troglodytes) dan bonobo (Pan Paniscus). Orangutan memiliki ketergantungan dengan kondisi hutan yang masih asri dan ekologi alam yang terjaga, serta merupakan primata frugivorus (hewan yang memakan buah-buahan). Orangutan memerlukan buah-buahan sebagai sumber makanan utamanya dan bahan makanan ini sesungguhnya sangat mudah diperoleh di hutan (Prayogo et al., 2014).

Kabupaten Langkat merupakan salah satu tujuan daerah wisata Provinsi Sumatera Utara. Selama periode tahun 2014-2016 jumlah wisatawan yang datang ke Kabupaten Langkat mengalami penurunan yang cukup signifikan baik yang berasal dari wisatawan domestik maupun wisatawan mancanegara. Badan Pusat Statistik Kabupaten Langkat mencatat bahwa jumlah wisatawan domestik tahun 2014 mencapai 40433 orang menurun menjadi 13715 Tahun 2016, sedangkan wisatawan mancanegara dari 8567 orang Tahun 2014 turun menjadi 4855 orang tahun 2016. Jumlah wisatawan yang datang ke Kabupaten Langkat mengalami penurunan dari tahun 2014 sebesar 62\% sampai tahun 2016 (BPSKL, 2017a). Wisata konservasi orangutan di Bukit Lawang merupakan konservasi nasional yang berada di kawasan hutan lindung Taman Nasional Gunung Leuseur Kabupaten Langkat, Sumatera Utara dan telah menjadi salah satu obyek alam yang sangat menarik. Konservasi ini memiliki karakteristik khusus yaitu dihuni oleh Orangutan Sumatera (Pongo abelii).

Penurunan kunjungan wisata konserrvasi Orangutan di Bukit Lawang (WKOB) diakibatkan oleh beberrapa hal diantaranya: terjadinya pengaturan keuangan antarapusat dan daerah, sentralisasi menjadi desentralisasi dimana setiap daerah berusaha untuk mencari sumber pendapatan daerah dari wilayahnya (keariftan lokal) sehingga obyek wisata yang memiliki warisan yang tinggi tidak mendapat perhatian yang optimal dari Pemerintah Daerah setempat. Akibatnya lingkungan penyangga tereksploitasi sebagai contoh konversi lahan untuk perkebunan sehingga mengancam keberadaan habitat yang ada di dalamnya, penebangan kayu illegal yang berdampak banjir bandang, penambangan batu kali (galian C) di Sungai Bahorok dan kesadaran masyarakat dalam menjaga kebersihan dan kelestarian sungai yang rendah. WKOB ini adalah wisata minat khusus yang banyak diminati oleh wisatawan mancanegara yang berasal dari seluruh dunia, khususnya Eropa.

Menurut kajian dari Kementerian Pariwisata, menurunnya kunjungan wisman dari pasar Eropa antara lain Jerman, Perancis, Inggris, dan Belanda pada November 2014 sampai tahun 2015, antara lain karena dampak dari melemahnya mata uang Euro terhadap dolar AS, sehingga banyak yang mengalihkan liburannya ke negara terdekat. Selain itu, karena sebagian besar wisatawan yang berkunjung ke Kabupaten Langkat, khususnya Wisata Konservasi Orangutan Bukit Lawang datang melalui Malaysia dan Singapura. Sementara pada saat bersamaan di Malaysia juga terjadi penurunan kunjungan wisman, yang salah satu penyebabya akibat pengaruh cuaca tingginya curah hujan yang menyebabkan banjir bandang dan tanah longsor di beberapa negara bagian Malaysia (Kompas, 2015).

Sismudjito dan Daulay (2018) telah melakukan penelitian pengembangan masyarakat berbasis sektor pariwisata untuk pertumbuhan ekonomi Bukit Lawang Kabupaten Langkat menggunakan metode penelitian partisipatif. Hasil dari proses dedikasi, masyarakat di Bukit lawang memanfaatkan sumber daya alam sebagai kegiatan ekonomi. Sumber daya alam tersebut yakni sungai Bahorok di Bukit Lawang, Kabupaten Langkat, yang kini juga dikenal sebagai lokasi rekreasi bagi wisatawan. Berdasarkan penelitian tersebut diketahui terjadi peningkatan ekonomi masyarakat utamanya dari pengelolaan atraksi Sismudjito dan Daulay (2018). Namun demikian penelitian tersebut belum menunjukkan secara jelas nilai ekonomi yang didapatkan dari wisata konservasi orangutan di Bukit Lawang tersebut.

Dalam pengembangan strategi dan kebijakan ekowisata maka sangat perlu juga diketahui nilai ekonomi wisata konservasi orangutan di wilayah Bahorok tersebut melalui valuasi ekonomi. Terkait penilaian ekonomi 
Krause et al. (2017) telah melakukan penilaian jasa ekonomi ekosistem berdasarkan persepsi komunitas pedesaan di Ethiopia yang menyimpulkan bahwa terdapat perubahan signifikan dalam penggunaan lahan dari waktu ke waktu karena sumber mata pencaharian utama dalam komunitas kemitraan. Penilitian Krieger (2001) telah menilai ekonomi ekosistem hutan dari ketersediaan air (watersheet service), stabilisasi tanah dan kontrol erosi, kualitas udara, pengaturan iklim dan carbon, keanekaragaman hayati, rekreasi dan parawisata/turisme, produk komersial hutan non kayu, dan nilai budaya. Pendekatan yang digunakan dalam mengukur nilai tersebut adalah metode biaya perjalanan (travel cost method) dengan pendekatan harga hedonic (hedonic approach). Pada penelitian ini valuasi eknonomi didekati melalui Cost Benefit Analysis yang merupakan sebuah pendekatan dengan proses yang sistematis dan analitis dengan membandingkan manfaat dan biaya dalam mengevaluasi keinginan suatu proyek atau program yang bersifat sosial. Penelitian ini bertujuan untuk mengetahui faktor-faktor yang menjadi kendala kunci dalam pengelolaan wisata konservasi orangutan di Bukit Lawang serta mengetahui strategi alternatif kebijakan yang tepat untuk mengatasi kendala pengelolaan kawasan wisata konservasi orangutan di Bukit Lawang.

\section{METODE}

\section{Lokasi dan Waktu Penelitian}

Penelitian ini dilaksanakan di Balai Besar Taman Nasional Gunung Leuser (BBTNGL), Seksi Pengelolaan Taman Nasional (SPTN) Wilayah V Bahorok Kabupaten Langkat Provinsi Sumatera Utara, tepatnya Wisata Konservasi Bukit Lawang. Lokasi wisata merupakan pusat konservasi khusus Orangutan Sumatera Langka dan sudah banyak dikunjungi wisatawan mancanegara sejak dibukanya wisata alam di Bukit Lawang, Langkat pada tahun 1985 hingga saat ini. Pada tahun tersebut baru dibuka secara resmi untuk umum sebagai obyek wisata minat khusus (wisata konservasi). Namun dalam beberapa tahun terakhir ini terjadi penurunan dari wisatawan mancanegara dan peminat dari wisata domestik, padahal terdapat objek wisata konservasi orangutan yang langka di dunia.

\section{Metode Pengumpulan Data}

Jenis data yang digunakan dalam penelitian ini adalah data primer. Data primer pada penelitian diperoleh dari hasil jastifikasi pakar melalui wawancara secara mendalam dan diskusi-diskusi dengan key person atau pakar berdasarkan kuesioner Interpretative Structural Modelling (ISM) dan Analitical Hierarchy Process (AHP). Kuesioner dirancang berdasarkan literatur, kunjungan lapangan dan diskusi-diskusi serta konfirmasi dengan para key person/pakar. Jastifikasi pakar/key person yang dituangkan dalam masing kuesioner kemudian diolah dengan software ISM untuk hasil kuesioner ISM dan kedalam Expert Choice 2000 untuk data justifikasi pakar AHP. Key person/pakar yang memberikan jastifikasi dalam penelitian ini sebanyak 11 orang, yang mewakili BBTNGL, yaitu dari SPTN V sebanyak empat orang (kepala SPTN V, dua Pengolahan Data Perencanaan, Perlindungan \& Pengawetan TN Wilayah, polisi hutan senior), satu kepala Bidang Perencanaan BBTNGL, kasie operasional dan pelayanan, satu orang pakar konservasi dan ekowisata, Tokoh masyarakat Bukit Lawang, Pelaku Pariwisata (pengusaha tour \& travel serta mewakili asosiasi pariwisata Bukit Lawang), Konsultan Pariwisata dan Pakar analisis pariwisata dan lingkungan.

\section{Metode Analisis Data}

Metode pengolahan data dilakukan dengan menginputkan data justifikasi masing-masing kuesioner pendapat pakar ke dalam piranti lunak (software) System ISM untuk kuesioner ISM, kemudian lakukan proses running sampai keluar hasil akhir dalam bentuk gambar matriks driver power-dependence elemen dan gambar strukturnya. ISM digunakan untuk melakukan analisis kendala dalam pengelolaan wisata konservasi Orangutan Bukit Lawang dan kelembagaan WKOB agar efektif. Penysunan elemen-elemen dan sub-elemen untuk kebutuhan analisis ISM dalam penelitian ini, disusun berdasarkan literatur, kondisi di lapangan dan konfirmasi 
beberapa pakar/key person yang benar-benar memahami WKOB, terutama pengelola SPTN V, pelaku usaha pariwisata setempat dan tokoh masyarakat di Bukit Lawang. Berdasarkan hasil penelitian hanya empat elemen yang diperlukan untuk menjawab tujuan penelitian dari Sembilan elemen dalam Saxena (1990), yaitu elemen kendala utama, elemen stakeholder yang terlibat (kelembagaan), elemen kebutuhan program dan elemen perubahan yang harus dilakukan. Dalam penyusunan elemen dan sub-elemen, peneliti melakukan kajian literature, kunjungan awal dan observasi langsung ke lokasi penelitian dan melakukan konfirmasi kepada para pakar/key person.

Empat elemen utama yang dianalisis dengan menggunakan ISM adalah 1). Lembaga atau stakeholder yang terlibat dalam pengelolaan WKOB, 2) Kendala utama WKOB, 3) Kebutuhan program WKOB, dan 4) Perubahan yang harus dilakukan. Keempat elemen tersebut masing-masing dijabarkan ke dalam bebepa subelemen yang diperoleh dari kajian beberapa literature dan pengamatan langsung di lapangan serta konfirmasi pakar, kemudian dituangkan dalam bentuk kuesioner ISM. Berdasarkan kuesioner ISM diperoleh jastifikasi masing-masing pakar berupa matriks $\mathrm{V}, \mathrm{A}, \mathrm{X}$ dan $\mathrm{O}$.

Berdasarkan hasil penelitian baik kajian literatur, hasil kunjungan lapang dan konfirmasi pakar subelemen/unsur masing-masing elemen adalah sebagai berikut. Lembaga atau stakeholder yang terlibat dalam pengelolaan WKOB terdiri dari unsur: 1). Kementerian Lingkungan Hidup dan Kehutanan, 2) Kementerian Pariwisata, 3) Balai Besar Taman Nasional Gunung Leuser (BBTNGL), 4) Dinas Kehutanan dan Perkebunan Kabupaten Langkat, 5) Dinas Pendapatan Daerah Kabupaten Langkat, 6) Badan Lingkungan Hidup Kabupaten Langkat, 7) Badan Perencanaan dan Pembangunan Daerah Kabupaten Langkat (Bappeda), 8) Dinas Pariwisata dan Kebudayaan Kabupaten Langkat, 9) Lembaga Swadaya Masyarakat, 10) Lembaga Pendidikan/Universitas, 11) Pelaku Bisnis Pariwisata, 12) Masyarakat, dan 13) Wisatawan.

Elemen Kendala utama WKOB terdiri dari (1) Ancaman kerusakan lingkungan TNGL (galian C dan sampah), (2) Belum terintegrasinya retribusi dan tarif masuk, (3) Buruknya infrastruktur menuju WKOB, (4) Kurangnya sarana dan prasarana serta fasilitas, (5) Konflik satwa liar, (6) Kurangnya penunjuk arah, (7) Banyaknya pintu masuk, (8) Alih fungsi lahan, (9) Kurangnya peran stakeholders terutama Pemerintah, (10) Kurang tegasnya penegakan peraturan terutama terkait dengan lingkungan dan kebersihan, (11) Kurangnya informasi dan promosi wisata, (12) Masih rendahnya pola pikir dan kesadaran masyarakat akan pentingnya ekowisata dan konservasi.

Elemen Kebutuhan program WKOB terdiri dari sub-elemen: (1) Pengembangan kebijakan kerjasama dengan Kementerian dan Pemerintah Daerah, (2) SDM pengelolaan yang berkualitas, (3) Sarana dan prasarana pengelolaan kawasan konservasi, (4) Pendidikan dan pelatihan bagi masyarakat, (5) Penangkaran satwa, (6) Integrasi program konservasi antar stakeholders, (7) Tenaga penyuluh dan pendamping untuk masyarakat, (8) Pemberian mata pencaharian alternatif bagi masyarakat, (9) Perbaikan sarana dan prasarana serta fasilitas dan (10) Peningkatan infrastruktur. Elemen Perubahan yang harus dilakukan harus dilakukan (1) Sinkronisasi dan kerjasama antar stakeholders dalam meningkatkan pengelolaan dan pelayanan wisata konservasi, (2) Menyediakan penangkaran satwa, (3) Menerapkan sanksi tegas terhadap perusakan lingkungan, (4) Penerapan kebijakan tiket masuk terintegrasi dan pelayanan satu pintu masuk, (5) Sosialisasi kepada masyarakat tentang perizinan dan pemanfaatan sumberdaya hutan, (6) Pengadaan sarana dan prasarana serta fasilitas di kawasan konservasi, (7) Diadakannya event rutin seluruh stakeholders dalam upaya menjaga lingkungan, (8) Peningkatan pengetahuan dan pembinaan terhadap masyarakat tentang manfaat hutan termasuk ekowisata, (9) Peningkatan keterampilan dan kreativitas masyarakat, (10) Penataan lingkungan hidup, ketertiban dan kebersihan serta kenyamanan dan (11) Penyediaan sarana dan prasarana untuk pemeliharaan lingkungan.

Sementara untuk alternatif solusi pengeloalan WKOB menggunakan AHP dengan bantuan piranti lunak Expert Choice 2000. Data yang diolah pada AHP menggunakan Expert Choice 2000 berdasarkan jastifikasi seluruh pakar. 


\section{HASIL DAN PEMBAHASAN}

\section{Analisis Kelembagaan dan Kendala dengan ISM}

Struktur elemen analisis kendala dan peluang dalam pengelolaan Wisata Konservasi Orangutan Bukit Lawang (WKOB) dianalisis dengan metode ISM berdasarkan jastifikasi ke-11 pakar/key person yang telah diwawancara secara mendalam dengan instrumen kuesioner ISM. Hasil jastifikasi masing-masing pakar pada empat elemen utama yang harus diperhatikan dalam menentukan kebijakan, yaitu 1). Lembaga yang terlibat dalam pengelolaan WKOB, 2) Kendala utama WKOB, 3) Kebutuhan program WKOB, dan 4) Perubahan yang harus dilakukan yang berupa matriks V, A, X dan O yang diinputkan ke dalam sistem ISM. Output dari sistem ISM berupa klasifikasi penilaian berdasarkan diagram Kartesius ISM, nilai driver power (DP) dan nilai dependence (D) dan membentuk struktur elemen. Secara garis besar klasifikasi elemen tersebut digolongkan dalam empat sektor yaitu (Eriyatno 2003 dan Marimin 2008):

1. Sektor I : Weak driveri-weak dependent variabels (AUTONOMUS). Sub-elemen yang masuk dalam sektor ini umumnya tidak berkaitan dengan sistem, dan mungkin mempunyai hubungan sedikit, meskipun hubungan tersebut bisa saja kuat.

2. Sektor I : Weak driveri-weak dependent variabels (AUTONOMUS). Sub-elemen yang masuk dalam sektor ini umumnya tidak berkaitan dengan sistem, dan mungkin mempunyai hubungan sedikit, meskipun hubungan tersebut bisa saja kuat.

3. Sektor II : Weak driver-strongly dependent variabels (DEPENDENT). Umumnya sub-elemen yang masuk dalam sektor ini adalah sub-elemen yang tidak bebas.

4. Sektor III : Strong driver-strongly dependent variabels (LINKAGE). Sub-elemen yang masuk dalam sektor ini harus dikaji secara hati-hati, sebab hubungan antar sub-elemen tidak stabil. Setiap tindakan pada sub-elemen akan memberikan dampak terhadap sub-elemen lainnya dan pengaruh umpan baiknya dapat memperbesar dampak.

5. Sektor IV : Strong driver-weak dependent variabels (INDEPENDENT). Sub-elemen yang masuk dalam sektor ini merupakan bagian sisa dari sistem dan disebut perubah bebas.

Hasil analisis dengan ISM untuk kendala dan peluang dalam pengelolaan wisata konservasi Orangutan di Bukit Lawanng berupa elemen 1) Lembaga yang terlibat dalam pengelolaan WKOB, 2) Kendala utama WKOB, 3) Kebutuhan program WKOB, dan 4) Perubahan yang harus dilakukan secara lengkap dijelaskan berikut.

\section{Lembaga atau Stakeholder yang Terlibat}

Elemen lembaga yang terlibat dalam rangka mengetahui kendala dan peluang pengelolaan WKOB berdasarkan kajian literature, pengamatan langsung dan konfirmasi para pakar/key person terdiri dari 13 sub elemen, yaitu 1). Kementerian Lingkungan Hidup dan Kehutanan, 2) Kementerian Pariwisata, 3) Balai Besar Taman Nasional Gunung Leuser (BBTNGL), 4) Dinas Kehutanan dan Perkebunan Kabupaten Langkat, 5) Dinas Pendapatan Daerah Kabupaten Langkat, 6) Badan Lingkungan Hidup Kabupaten Langkat, 7) Badan Perencanaan dan Pembangunan Daerah Kabupaten Langkat (Bappeda), 8) Dinas Pariwisata dan Kebudayaan Kabupaten Langkat, 9) Lembaga Swadaya Masyarakat, 10) Lembaga Pendidikan/Universitas, 11) Pelaku Bisnis Pariwisata, 12) Masyarakat, dan 13) Wisatawan. Hasil analisis dengan sistem ISM berupa matriks driver power-dependence untuk elemen Lembaga atau kelompok yang terlibat dalam pengelolaan WKOB dapat dilihat pada Gambar 1.

Hasil analisis matriks pada Gambar 1 menunjukkan bahwa sub elemen Kementerian Lingkungan Hidup dan Kehutanan, Kementerian Pariwisata dan Balai Besar Taman Nasional Gunung Leuser berada pada sektor 
IV (independent), sub elemen ini sebagai driver power (daya pendorong utama paling besar dengan tingkat ketergantungan terhadap sub elemen lembaga atau kelompok yang terlibat dalam pengelolaan WKOB lainnya paling rendah). Artinya, lembaga utama yang terlibat dalam pengelolaan WKOB adalah Kementerian Lingkungan Hidup dan Kehutanan, Kementerian Pariwisata dan Balai Besar Taman Nasional Gunung Leuser. Ketiga lembaga tersebut akan mempengaruhi lembaga yang lain (terkait sub elemen lainnya yang dikaji).

Sub elemen Dinas Kehutanan dan Perkebunan Kabupaten Langkat, Dinas Pendapatan Daerah Kabupaten Langkat, Badan Lingkungan Hidup Kabupaten Langkat, Badan Perencanaan dan Pembangunan Daerah Kabupaten Langkat, Dinas Pariwisata dan Kebudayaan Kabupaten Langkat dan Lembaga Pendidikan/Universitas berada pada sector III/linkage yang merupakan kekuatan penggerak yang besar terhadap pengelolaan WKOB. Artinya, yang menjadi faktor penggerak atau yang dapat memberikan dampak lebih besar terhadap lembaga lainnya adalah sub elemen yang telah disebutkan. Sub elemen Lembaga Swadaya Masyarakat, Pelaku bisnis pariwisata, Masyarakat dan Wisatawan berada pada (sector II/dependent) keberadaan sub elemen ini bergantung pada sub elemen lainnya. Artinya, keempat sub elemen dipengaruhi oleh lembaga atau kelompok yang menjadi kunci utama (daya pendorong terkuat). Secara lengkap struktur hirarki elemen Lembaga yang terlibat dalam pengelolaan WKOB dapat dilihat pada Gambar 2.

Lembaga yang terlibat dalam pengembangan wisata konservasi di Bukit Langkat sangat dibutuhkan dalam upaya peningkatan pariwisata di Bukit Lawang, selain untuk menjaga keberlangsungan wisata konservasi orangutan juga agar dapat bekerjasama dalam meningkatkan promosi (Yusnikusumah dan Sulystiawati 2016).

\section{Kendala Utama}

Hasil analisis dengan sistem ISM berupa struktur hierarki untuk elemen Kendala utama dalam pengelolaan WKOB dapat dilihat pada Gambar 3. Hasil analisis menunjukkan bahwa sub elemen Belum terintegrasinya retribusi dan tarif masuk, Buruknya infrastruktur menuju WKOB, Kurangnya sarana dan prasarana serta fasilitas, dan Banyaknya pintu masuk berada pada sektor IV (independent), sub elemen ini sebagai driver power (daya pendorong utama paling besar dengan tingkat ketergantungan terhadap sub elemen Kendala utama dalam pengelolaan WKOB lainnya paling rendah). Artinya, kendala utama dalam pengelolaan WKOB adalah belum terintegrasinya retribusi dan tarif masuk, buruknya infrastruktur menuju WKOB, kurangnya sarana dan prasarana serta fasilitas, dan banyaknya pintu masuk. Keempat kendala tersebut akan mempengaruhi kendala yang lain. Buruknya pengelolaan terhadap sarana dan prasarana kawasan wisata di Bukit Lawang sesuai dengan penelitian yang dilkukan oleh Idihan (2004).

Sub elemen kurangnya peran stakeholders terutama pemerintah, kurang tegasnya penegakan peraturan terutama terkait dengan lingkungan dan kebersihan, kurangnya informasi dan promosi wisata, dan masih rendahnya pola pikir dan kesadaran masyarakat akan pentingnya ekowisata dan konservasi berada pada sector III/linkage yang merupakan kekuatan penggerak yang besar terhadap pengelolaan WKOB. Artinya, yang menjadi faktor penggerak atau yang dapat memberikan dampak lebih besar terhadap kendala utama lainnya adalah sub elemen kurangnya peran stakeholders terutama Pemerintah Daerah, kurang tegasnya penegakan peraturan terutama terkait dengan lingkungan dan kebersihan, kurangnya informasi dan promosi wisata, dan masih rendahnya pola pikir dan kesadaran masyarakat akan pentingnya ekowisata dan konservasi. Sub elemen ancaman kerusakan lingkungan TNGL (galian C dan sampah), konflik satwa liar, kurangnya penunjuk arah dan alih fungsi lahan berada pada (sector II/dependent) keberadaan sub elemen ini bergantung pada sub elemen lainnya. Artinya, keempat sub elemen dipengaruhi oleh lembaga atau kelompok yang menjadi kunci utama (daya pendorong terkuat). 


\section{Kebutuhan Program}

Pada elemen Kebutuhan program dalam upaya pengelolaan WKOB, hasil analisis dengan sistem ISM berupa struktur hierarki untuk elemen kebutuhan program dalam pengelolaan WKOB dapat dilihat pada Gambar 4. Hasil analisis ISM menunjukkan bahwa sub elemen Pengembangan kebijakan kerjasama dengan Kementerian dan pemerintah daerah, SDM pengelola yang berkualitas, dan Sarana dan prasarana pengelolaan kawasan konservasi driver power (daya pendorong utama) dan fakto kunci. Artinya, Kebutuhan program dalam pengelolaan WKOB adalah Pengembangan kebijakan kerjasama dengan Kementerian dan pemerintah daerah, SDM pengelola yang berkualitas, dan Sarana dan prasarana pengelolaan kawasan konservasi. Ketiga kebutuhan program tersebut akan mempengaruhi kebutuhan program yang lain (terkait sub elemen lainnya yang dikaji). Hal ini sejalan dengan penelitian yang dilakukan oleh Siburian (2006), pemerintah daerah telah menerbitkam SK Bupati Kepala Daerah Tingkat II 071-673/SK/tahun 1998 tanggal 23 September 1998 tentang Pembentukan Panitia Sosialisasi Komitmen Tokoh Masyarakat dan Adat terhadap Ekosistem Leuser, hal tersebut dilakukan dalam upaya kepedulian terhadap kelestarian TNGL terutama di Bukit Lawang.

Sub elemen Pendidikan dan pelatihan bagi masyarakat, Integrasi program konservasi antar stakeholder, Tenaga penyuluh dan pendamping untuk masyarakat, Perbaikan sarana dan prasarana serta fasilitas, Peningkatan infrastruktur berada pada sector III/linkage yang merupakan kekuatan penggerak yang besar terhadap pengelolaan WKOB. Sub elemen tersebut harus dikaji dengan hati-hati, sebab hubungan antar sub elemen tidak stabil. Setiap tindakan pada sub elemen bisa memberikan dampak pada sub elemen lain, dan umpan balik memperbesar dampak. Artinya, yang menjadi faktor penggerak atau yang dapat memberikan dampak lebih besar terhadap kebutuhan program lainnya adalah sub elemen pendidikan dan pelatihan bagi masyarakat, integrasi program konservasi antar stakeholder, tenaga penyuluh dan pendamping untuk masyarakat, perbaikan sarana dan prasarana serta fasilitas, peningkatan infrastruktur.

Sub elemen penangkaran satwa, dan pemberian mata pencaharian alternatif bagi masyarakat berada pada (sector II/dependent) keberadaan sub elemen ini bergantung pada sub elemen lainnya. Artinya, kedua sub elemen dipengaruhi oleh lembaga atau kelompok yang menjadi kunci utama (daya pendorong terkuat).

\section{Perubahan yang Harus Dilakukan}

Pada elemen perubahan yang memungkinkan dapat dilakukan dalam upaya pengelolaan WKOB hasil analisis ISM menunjukkan bahwa sub elemen sinkronisasi dan kerjasama antar stakeholder dalam meningkatkan pengelolaan dan pelayanan wisata konservasi, dan penerapan kebijakan tiket masuk terintegrasi dan pelayanan satu pintu masuk berada pada sektor IV (independent), sub elemen ini sebagai driver power (daya pendorong utama paling besar) dan faktor kunci dalam pengelolaan WKOB. Artinya, perubahan yang memungkinkan dapat dilakukan dalam pengelolaan WKOB agar efektif dan optimal adalah melakukan sinkronisasi dan kerjasama antar stakeholder dalam meningkatkan pengelolaan dan pelayanan wisata konservasi. Kedua perubahan yang memungkinkan tersebut akan mempengaruhi perubahan yang lain (terkait sub elemen lainnya yang dikaji).

Sub elemen menerapkan sangsi tegas terhadap perusakan lingkungan, sosialisasi kepada masyarakat tentang perizinan dan pemanfaatan sumberdaya hutan, diadakannya event rutin seluruh stakeholder dalam upaya menjaga lingkungan, peningkatan pengetahuan dan pembinaan terhadap masyarakat tentang manfaat hutan termasuk ekowisata, peningkatan keterampilan dan kreativitas masyarakat berada pada sector III/linkage yang merupakan kekuatan penggerak yang besar terhadap pengelolaan WKOB. Sub elemen tersebut harus dikaji dengan hati-hati, sebab hubungan antar sub elemen tidak stabil. Setiap tindakan pada sub elemen bisa memberikan dampak pada sub elemen lain, dan umpan balik memperbesar dampak. Artinya, yang menjadi faktor penggerak atau yang dapat memberikan dampak lebih besar terhadap kebutuhan program lainnya adalah sub elemen menerapkan sangsi tegas terhadap perusakan lingkungan, sosialisasi kepada masyarakat tentang perizinan dan pemanfaatan sumberdaya hutan, diadakannya event rutin seluruh stakeholder dalam upaya 
menjaga lingkungan, peningkatan pengetahuan dan pembinaan terhadap masyarakat tentang manfaat hutan termasuk ekowisata, peningkatan keterampilan dan kreativitas masyarakat.

\section{Analisis Alternatif Solusi Pengelolaan WKOB dan Kebijakan}

Analisis alternatif solusi dalam rangka pengelolaan WKOB berdasarkan jastifikasi para pakar sebanyak 11 orang orang. Jastifikasi pakar diperoleh berdasarkan hasil pengisian kuesioner AHP melalui wawancara mendalam langsung. Goal dari analisis ini adalah pemilihan alternatif solusi pengelolaan WKOB, dengan kriteria Efisiesi biaya, kriteria kedua Ramah Lingkungan dan Efektifitas dalam pengelolaan. Penyusunan hirarki AHP melalui dekomposisi permasalahan berdasarkan literatur, pengamatan langsung peneliti saat beeberapa kali berkunjung ke WKOB dan dikonfirmasi dengan beberapa orang pakar yang benar-benar faham dengan WKOB.

Jastifikasi masing-masing pakar berupa angka perbandingan berpasangan (pairwise comparison) yang diperoleh dalam matriks kuesioner, kemudian diinputkan ke dalam piranti lunak Exper Choice 2000. Kuesioner setiap pakar setelah diinputkan, kemudian langsung dikompilasi sampai diperoleh sintesis hasilnya berupa bobot komposit untuk setiap alternatif strategi, faktor dan sub-faktornya. Hasil akhir jastifikasi seluruh pakar AHP yang diolah diperoleh dengan melakukan kompilasi seluruh pakar yang diinputkan ke dalam piranti lunak Expert Choice, dengan cara melakukan kompilasi pendapat gabungan, dalam piranti lunak tersebut sudah tersedia menu combine individual.

Berdasarkan hasil akhir analisis AHP dengan piranti lunak Expert choice menurut jastifikasi seluruh pakar, menunjukkan bahwa alternatif solusi pengelolaan WKOB (hasil sintesis goal) utama adalah pengelolaan wisata terintegrasi dan profesional serta berkelanjutan dengan bobot sebesar 0.419 (41.9\%). Artinya alternatif utama yang dilakukan untuk mengelola WKOB adalah dengan cara pengelolaan wisata yang terintegrasi dan dijalankan secara professional serta berkelanjutan. Alternatif selanjutnya adalah melakukan Pembinaan dan pemberdayaan masyarakat/wisatawan dengan bobot sebesar 0.263 (26.3\%), alternatif yang ketiga adalah Penyediaan infrastruktur, sarpras dan fasilitas dengan bobot sebesar 0.062 (6.3\%), sedangkan alternatif keempat dan kelima adalah Promosi wisata dan penyebaran informasi (0.097) dan Pengembangan atraksi dan produk (0.062). Secara keseluruhan, hasil olah data disajikan pada Gambar 6.

Dalam usaha pengembangan wisata alam minat khusus atau ekowisata, partisipasi pemerintah sangat diharapkan sekali terutama dalam menyusun rencana tata ruang dengan baik dan matang. Beberapa usaha Pemerintah dalam pengendalian kepariwisataan yakni pengembangan wisata alam di Bukit Lawang seperti yang disampaikan oleh Sinuhaji (2009), adalah: menyediakan kantor tourist information, pembinaan terhadap industri partiwisata di Bukit Lawang dan sekitarnya, mengurus atau mengeluarkan surat izin masuk kawasan Hutan Taman Nasional, membuat tanda-tanda larangan dilokasi kegiatan wisata lintas alam dan membuat rambu - rambu pariwisasta menuju objek wisata Bukit Lawang

Alternatif solusi yang terpilih diperoleh dari sintesis pengolahan AHP pendapat seluruh pakar dalam pengelolaan WKOB, yaitu pengelolaan wisata terintegrasi dan professional serta berkelanjutan $(0,419)$ dipengaruhi dan harus didukung beberapa kriteria, terutama kriteria Efektivitas dengan bobot sebesar 0.540 (54\%). Artinya dalam pengelolaan WKOB, khususnya untuk pengelolaan wisata konservasi yang terintegrasi, professional dan berkelanjutan faktor "efektifitas" menjadi hal utama yang harus diperhatikan, baik itu efektifitas dari sisi ketersediaan infrastruktur, sarana dan prasarana fasilitas pendukung, kerjasama antar pemangku kepentingan, kebijakan, dan lain-lainnya. Faktor lain Ramah lingkungan dengan bobot sebesar 0.297 (29.7\%), dan Efisiensi biaya dengan bobot sebesar 0.163 (16.3\%) juga harus diperhatikan agar solusi strategis dalam pengelolaan WKOB menjadi optimal dan dapat diterapkan. Tentunya untuk keberhasilan implementasi strategi tersebut harus benar-benar di dukung oleh peran lembaga/stake holder yang terlibat sebagai faktor kunci, yaitu Kementerian Lingkungan Hidup dan Kehutanan, Kementerian Pariwisata dan Balai Besar Taman Nasional Gunung Leuser (SPTN V Bukit Lawang) serta Pemda (Sumut maupun Kabupaten Langkat) melalui Dinas Pariwisata. 


\section{Implikasi Manajerial}

Sejak diberlakukannya sistem pengelolaan pemerintahan dari sentralisasi menjadi desentralisasi dengan harapan daerah bisa membangun wilayahnya secara mandiri sesuai dengan kearifan lokal masing-masing daerah yang akhirnya memacu kerja keras untuk mencari sumber APBD bagi daerahnya, apa yang dapat diperbaharui serta diberdayakan untuk mendapatkan keuntungan profit yang kemudian tanpa disadari atau tidak disadari memberikan akibat terhadap kerusakan lingkungan. Karena seringkali sumber daya alam di daerah yang lebih mudah untuk dieksploitasi menjadi sumber pendapatan dan sering melupakan dampak kerusakan yang pada akhirnya mengakibatkan bencana alam bagi daerah tersebut yang tentunya kembali malah merugikan masyarakat setempat. Maksud dari eksplorasi/eksploitasi sumber daya alam untuk mendukung kehidupan yang lebih baik dan sejahtera namun karena melupakan bahwa sejatinya manusia hidup harus berdampingan dengan alam sehingga masyarakat menjadi korban dari eksploitasi tersebut. Biodiversity yang dimiliki oleh alam Indonesia sejatinya dapat menjadi sumber kekayaan bukan semata keuntungan profit dengan mendatangkan wisatawan tetapi juga kekayaan pengetahuan yang dapat memberikan kesadaran bagi masyarakat, dengan kekayaan biodiversity yang dimiliki Indonesia menjadi sebuah warisan yang tidak dimiliki negara lain, dari nilai heritage tentu ini sangat mahal dan tidak dapat dinilai dengan uang untuk keberlangsungan hidup ke depan.

Dalam hal ini Pemerintah Daerah juga terus memastikan dengan tegas batas zona hutan konservasi Orangutan dengan kebun masyarakat agar tidak terjadi konflik satwa yang berakibat terganggunya habibat Orangutan, dan diharapkan mampu mengelola dan menerapkan kebijakan yang seimbang antara ekonomi, lingkungan dan masyarakat. Tidak semua sumber daya alam dieksploitasi besar-besaran demi mendapatkan sumber keuangan yang besar apabila pada akhirnya juga mengakibatkan bencana bagi lingkungan yang merugikan semua pihak. Dengan terjadinya bencana banjir bandang di sungai Bahorok pada tahun 2006 sebagai bukti dapat dijadikan pelajaran berharga bagi semua utama Pemerintah untuk kedepankan menjaga lingkungan atau sumber daya alam yang suistanable.

Dalam rangka mewujudkan pengelolaan wisata konservasi Orangutan di Bukit Lawang, perlu diperhatikan beberapa kendala utama diantaranya adalah belum terintegrasinya retribusi dan tarif masuk, buruknya infrastruktur menuju WKOB, kurangnya sarana dan prasarana serta fasilitas, dan banyaknya pintu masuk. Alternatif strategi kebijakan dalam mengatasi kendala pengelolaan WKOB adalah dengan pengelolaan wisata terintegrasi dan profesional serta berkelanjutan dengan memperhatikan faktor efektivitas, baik efektivitas dari sisi ketersediaan infrastruktur, sarana dan prasarana fasilitas pendukung, kerjasama antar pemangku kepentingan, kebijakan dan lain-lainnya. Faktor lain yang harus diperhatikan adalah ramah lingkungan dan efisiensi biaya agar solusi strategis dalam pengelolaan WKOB menjadi optimal dan dapat diterapkan. Tentunya untuk keberhasilan implementasi strategi tersebut harus benar-benar didukung oleh peran lembaga yang terlibat sebagai faktor kunci yaitu Kementerian Lingkungan Hidup dan Kehutanan, Kementerian Pariwisata dan Balai Besar Taman Nasional Gunung Leuseur (SPTN V Bukit Lawang) serta Pemda (Sumut maupun Kabupaten Langkat) melalui Dinas Pariwisata.

\section{SIMPULAN}

Berdasarkan hasil penelitian dapat disimpulkan bahwa: 1) Kendala utama dalam pengelolaan WKOB adalah (a) belum terintegrasinya retribusi dan tarif masuk, (b) buruknya infrastruktur menuju WKOB, (c) kurangnya sarana dan prasarana serta fasilitas dan (d) banyaknya pintu masuk. Keempat kendala tersebut akan mempengaruhi kendala yang lain (terkait sub elemen lainnya yang dikaji). Kendala lainnya kurangnya peran stakeholders terutama Pemerintah Daerah Kabupaten Langkat, kurang tegasnya penegakan peraturan terutama terkait dengan lingkungan dan kebersihan, kurangnya informasi dan promosi wisata, dan masih rendahnya pola pikir dan kesadaran masyarakat akan pentingnya ekowisata dan konservasi. Ancaman kerusakan lingkungan TNGL terutama galian $\mathrm{C}$ dan sampah merupakan hal yang tidak bisa dianggap sepele. Apabila 
tidak dilakukan tindakan tegas terutama Pemerintah Daerah Kabupaten Langkat maupun Pemerintah Provinsi Sumatera Utara maka hal ini dapat mengancam kerusakan lingkungan dan ekosistem. 2) Alternatif strategi kebijakan dalam mengatasi kendala pengelolaan WKOB adalah Pengelolaan wisata terintegrasi dan profesional dengan bobot sebesar 0.419 (41.9\%), artinya alternatif utama yang dilakukan untuk mengelola WKOB adalah dengan cara pengelolaan wisata yang terintegrasi dan dijalankan secara profesional. Alternatif selanjutnya adalah melakukan pembinaan dan pemberdayaan masyarakat/wisatawan dengan bobot sebesar $0.263(26.3 \%)$, alternatif yang ketiga adalah penyediaan infrastruktur, sarpras dan fasilitas dengan bobot sebesar $0.160(16 \%)$, sedangkan alternatif keempat dan kelima adalah promosi wisata dan penyebaran informasi (0.097) dan pengembangan atraksi dan produk (0.062).

\section{UCAPAN TERIMA KASIH}

Ucapan terima kasih disampaikan kepada seluruh pakar/key person yang telah bersedia memberikan jastifikasi dan berbagai masukan dalam penelitian ini dan kepada seluruh staf BBTNGL, khususnya pimpinan dan staf SPTN Bukit Lawang yang telah membantu memberika data dan menjadi sarana penelitian.

\section{DAFTAR PUSTAKA}

[BPSKL] Badan Pusat Statistik Kabupaten Langkat. 2016a. Kabupaten Langkat Dalam Angka 2017. Langkat (ID): Badan Pusat Statistik Kabupaten Langkat

[BPSKL] Badan Pusat Statistik Kabupaten Langkat. 2016b . Satistik Kabupaten Langkat 2017. Langkat (ID): Badan Pusat Statistik Kabupaten Langkat.

Alikodra, Hadi S. 2012. Konservasi Sumber Daya Alam dan Lingkungan. Yogjakarta (ID). UGM Press.

Eriyatno FS. 2007 . Riset Kebijakan: Metode Penelitian untuk Pascasarjana. Bogor (ID): IPB Press.

Hermawan H. 2017. Geowisata, Pengembangan Pariwisata Berbasis Konservasi. ICT [Internet].Idihan A. (2004). Upaya pengembangan kawasan wisata Bukit Lawang dalam Rangka Peningkatan pendapatan asli daerah kabupaten Langkat. Respository USU (ID): Medan.

Kompas. 2015. Diunduh pada 22 Februari 2019) Tersedia pada https://travel.kompas.com/read/2015/01/09/170500127/Kunjungan.Turis.Asing.Sempat.

Krieger, DJ. 2001. The Economic Value of Forest Ecosystem Service: A Review. Washington (US). The Wilderness Society.

Marimin. 2008. Pengambilan Keputusan Kriteria Majemuk. Jakarta (ID): PT Grasaindo.

P Alexander, Jan Philipp Dietrich, Hermann Lotze-Campen, David Klein, Nico Bauer, Michael Krause, Tim Beringer, Dieter Gerten and Ottmar Edenhofer. 2011. The economic potential of bioenergy for climate change mitigation with special attention given to implications for the land system. Environmental Research Letters. 6(3).

Prayogo H, Thohari AM, Sholihin DD, Prasetyo LB, Sugardjito. 2014. Karakter kunci pembeda antara Orangutan Kalimantan (Pongo pygmaeus) dengan Orangutan sumatera (Pongo abelii). Bionatura-Jurnal Ilmu-ilmu Hayati dan Fisik. 16(1) 61-68.

Saxena JP, P Vrat, Shusil. 1990. Hierarchy and classification of program plan element using interpretive structural modeling, System Practice. 5(6): 651-670.

Siburian R. 2006. Pengelolaan Taman Nasional Gunung Leuseur bagian Bukit Lawang berbasis promowisata. Jurnal masyarakat dan dan Budaya. 8(1): 67-100.

Sinuhaji. 2009. Pengendalian kawasan wisata alam dan hubungannya dengan ketataruangan. Jurnal Geografis. 1(1): 73-76.

Sismudjito, Daulay H. 2018. Community development based on tourism sectors for economic growth area Districts Bahorok District Langkat. IJTRD. 5(1): 85-88.

Warsono, Soetriono, Januar J. 2014. Strategi Pemberdayaan masyarakat sekitar hutan konservasi Taman Wisata Alam Gunung Baung dalam upaya mengurangi perambahan Hutan. JSEP. 7(2):62-7. 
Yusnikusumah R, Sulystiawati E. 2016. Evaluasi pengelolaan ekowisata di Kawasan Ekowisata Tangkahan Taman Nasional Gunung Leuser Sumatera Utara. Jurnal Perencanaan Wilayah dan Kota. 27(3): 173189. 